\title{
A new eco-friendly packaging material made of straw and bioplastic
}

\author{
Giuseppe Rossi, ${ }^{1}$ Leonardo Conti, ${ }^{1}$ Lorenzo Fiorineschi, ${ }^{2}$ Massimiliano Marvasi, ${ }^{3}$ Massimo Monti, ${ }^{1}$ \\ Federico Rotini, ${ }^{2}$ Marco Togni, ${ }^{1}$ Matteo Barbari ${ }^{1}$
}

${ }^{1}$ Department of Agricultural, Food and Forestry Systems, University of Florence; ${ }^{2}$ Department of Industrial

Engineering, University of Florence; ${ }^{3}$ Department of Biology, University of Florence, Italy

\begin{abstract}
Packaging waste is cause for serious concern. Each year hundreds of millions of tons of packaging are produced, therefore solutions that drastically reduce their environmental impact are urgently needed. While the recycling of metal, wood, paper and cardboard packaging has been significantly improved, an efficient recycling or disposal of some plastics is not yet feasible. The European Union implemented various regulations concerning packaging and packaging waste and set some relevant short to medium-term targets for recycling and disposal rates. Over the last decade, the global trend of the eco-sustainable packaging market is heading in the same direction. The aim of this research is to develop an innovative and sustainable composite material for the production of tertiary packaging based on the combination of natural fibres and biodegradable biopolymers. In particular, the experimental application entailed the creation of prototypes consisting of a material made of straw and biodegradable plastic Mater-Bi ${ }^{\circledR}$ which is named NeoPalea. The new material was prototyped to verify its physical characteristics and to determine its potential use to replace current not-biodegradable packaging. The results show a good match with the characteristics of current polymers, suggesting that this material can be used as a potential substitute in packaging applications.
\end{abstract}

Correspondence: Leonardo Conti, Department of Agricultural, Food and Forestry Systems, University of Florence, via San Bonaventura 13, 50134 Florence, Italy.

Tel.: +39.055.2755.626.

E-mail: leonardo.contil@unifi.it

Key words: Bio-packaging; straw; bioplastic; biodegradable; recycling; circular economy; composting.

Acknowledgements: The authors acknowledge the contribution of student Alessandro Hoffmann for the historical study and the definition of the material's name.

Received for publication: 10 June 2020.

Accepted for publication: 28 July 2020.

CC Copyright: the Author(s), 2020

Licensee PAGEPress, Italy

Journal of Agricultural Engineering 2020; LI:1088

doi:10.4081/jae.2020.1088

This article is distributed under the terms of the Creative Commons Attribution Noncommercial License (by-nc 4.0) which permits any noncommercial use, distribution, and reproduction in any medium, provided the original author(s) and source are credited.

\section{Introduction}

Conventional packaging materials derived from fossil sources are still the first choice in the industrial sector, despite growing concerns over their environmental impact (Tencati et al., 2016).

The production of large volumes of packaging material, the high energy consumption in production processes, the disposal of packaging waste in landfills and the persistence of these materials in the environment call for urgent and ecological solutions (Nordin and Selke, 2010). Bioplastics represent approximately one percent of about 360 million tons of plastic produced annually. This amount accounts for a third of all plastics produced worldwide. It has been estimated that in western industrialized countries, half of the goods sold on the market come with a plastic packaging (Bioplastic Market Data, 2019; www.european-bioplastics.org). In Europe (EU) alone, 70 million tons of packaging waste were produced in 2016, of which approximately 16.7 million tons were plastic waste (Dahlbo et al., 2018). As to the recovered materials, the largest portion was cellulose packaging, followed by wood, glass and plastic.

The development of packaging materials derived from renewable resources, such as organic waste, has received attention from governments and has become an urgent need in many industrial sectors (Babalis et al., 2013). Unlike synthetic polymers, biodegradable polymers such as cellulose, polysaccharides, proteins, from crops or biomass, can undergo physical, chemical, or biological decomposition. This feature makes them suitable for composting processes in households and industrial plants (Meeks et al., 2015). This will open up new opportunities for using waste, which are more advantageous than in landfills, both in environmental and in economic terms (Garrido et al., 2014). This approach will promote the implementation of a circular economy: strong innovation at the service of the packaging sector. To that end, the cereal industry and the straw deriving from it can offer opportunities that have attracted particular attention.

The current production of cereals totals up to about 2640 million tons harvested from over 700 million hectares, which generate a high amount of waste material from the entire cereal supply chain (FAO, 2020). The amount of straw produced annually in the cereal industry is about 2.1 billion tons. This creates a large quantity of residues that are sometimes burnt directly on the field, not to become an additional cost for cereal companies. This waste has little potential for reuse for agronomic needs (e.g. mulch and soil improvers) or zootechnical application (litter for livestock). This has led to a contraction of the market, with fluctuating prices and modest prospects in the collection and post-harvest phases (Conti et al., 2012; Russo and Verdiani, 2013). As an alternative to its use in the agricultural and zootechnical sectors, straw can be used in building materials and for heat production (Cherubini and Ulgiati, 2010). However, in all the above-mentioned sectors, there is no effective or consolidated production chain. Therefore, a comple- 
mentary objective of this research was to exploit a by-product of cereal production by transforming it from a waste product into a renewable resource. Bioplastics are also an important component of NeoPalea. By definition bioplastics are made of natural polymers (polysaccharides such as starch and cellulose), extracted from renewable agricultural resources (corn, potato, tapioca, rice, sugar cane, etc.) as well as lignocellulosic fibres (European Committee for Standardization, 2010). It has been estimated that 2.05 million tons of bioplastics were produced in 2017 (Brodin et al., 2017).

The aim of this study is the design of a new packaging material with a dual purpose: i) to obtain a new material from organic wastes with a view to decrease the environmental impact of plastics. ii) to develop a material, which is biodegradable and does not contribute to the plastic pollution. This material will be obtained from the combination of biodegradable compounds (straw and bioplastics), which are capable of providing ecological alternatives to the traditional tertiary packaging, adequate technical characteristics, an efficient use of resources and the treatment of packaging waste with a low environmental impact at the time of disposal (CONAI, 2017). This paper illustrates an innovative composite material called NeoPalea, its production process and the tests conducted for a preliminary characterization. The data obtained are used to discuss the potential of the proposed material as an alternative for the production of tertiary packaging.

\section{Materials and methods}

\section{Selection of materials}

Straw was chosen as one of the main wastes of cereal production with limited market value. Among all the bioplastics available on the market, the choice for prototype development fell on Mater$\mathrm{Bi}{ }^{\circledR}$ : a biodegradable and compostable bioplastic produced from corn starch by Novamont S.p.A. Its main disposal process is compost degradation, which is more convenient than incineration (Bhattacharyya et al., 2019). Lastly, all these components are compostable according to the EN 13432 standard (European Committee for Standardization, 2002).

\section{Manufacturing of the new material}

Straw can be used either as in the form of stems or to be cut to obtain $50 \mathrm{~mm}$ fragments with a water content that must not exceed $14 \%$. Chemical additives are not be used to either treat the fibrous material or the bioplastics during the production phases. The procedure will be carried out without the use of water.

The product-forming cycle (Figure 1A) starts with a plurality of bundles of straw arranged in parallel with each bundle wrapped in a sheet of Mater-Bi ${ }^{\circledR}$ to form elementary cylinders.
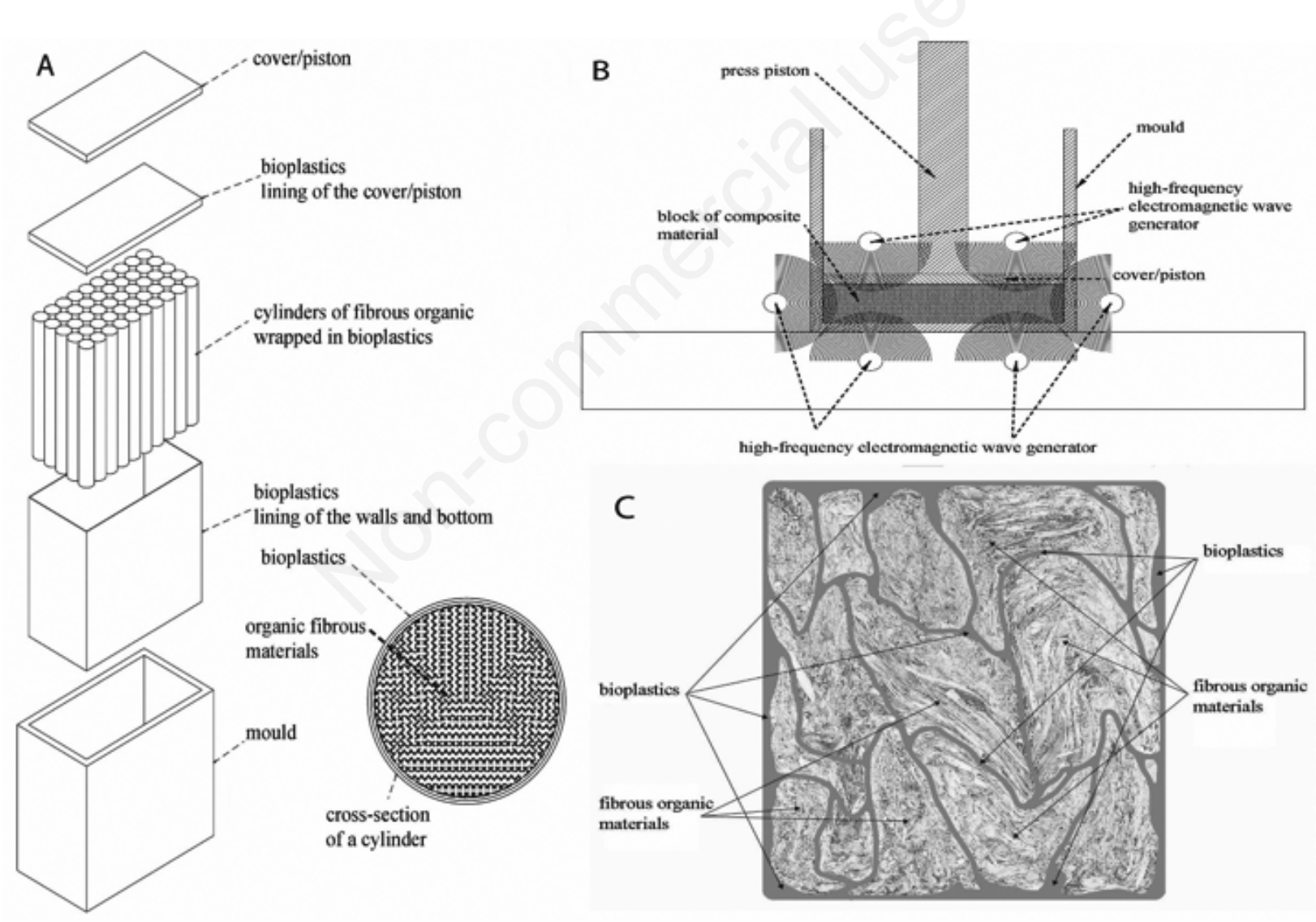

Figure 1. NeoPalea production process: (A) Assembly diagram and preparation of the components to manufacture a product with NeoPalea. The cylinders can have a length less than or equal to that of the mould walls and a variable median diameter. Both must be chosen according to the physical/mechanical characteristics to be obtained in the manufactured product; (B) Diagram for prototype preparation using a press and an electromagnetic wave generator; (C) Cross section of a prototype block with a special arrangement of the fibrous material and closed cells of bio-plastic material. The cells and the shells are in a state of tension and are made with Mater$\mathrm{Bi}{ }^{\circledR}$ (or the other biopolymers introduced in the previous section). The straw, the cells and the shell are configured to maintain a permanent state of coaction, with the fibrous organic material permanently compressed and the bioplastic shell permanently in tension. Therefore, the composite material maintains the internal tensions, compression and traction, each in one of the components. 
The cylinders are then inserted into a shell and compressed inside a mould by means of a piston. In this way, due to the compression inside the mould, the straw spreads its fibres in all directions. The cylinders must be in a sufficient number to fully fill the mould and be arranged vertically, or according to the direction of compression of the compression piston. When the fibres of the straw are compressed, they are free to disperse chaotically in all directions, not just horizontally, thus creating the finished product with an adequate resistance to any cutting actions. The moulding process is carried out by means of a press provided with a piston/actuation stem/cover, so that the latter compresses the materials inside. With the cover/piston maintained in the final position and therefore with the fibrous material in a state of compression, the process continues with a heating phase up to approximately $80^{\circ} \mathrm{C}$ by means of high-frequency electromagnetic radiation generators (in the $2000-4000 \mathrm{MHz}$ range with a power between $5000 \mathrm{~W}$ and $10000 \mathrm{~W}$ ) for a time ranging from $300 \mathrm{~s}$ to $900 \mathrm{~s}$, in order to achieve a complete blending of the bioplastic material and hence its bonding to the fibrous organic material. By way of example, in order to produce a block of $0.4 \times 0.8 \mathrm{~m}$ in size with a final volume of about $300 \mathrm{~kg} / \mathrm{m}^{3}$, it is necessary to have an irradiation of approximately $900 \mathrm{~s}$ with a power of about $6000 \mathrm{~W}$.

The generators are arranged to obtain a homogeneous diffusion of the electromagnetic waves inside the material mass contained in the mould (Figure 1B). In this way, the straw acquires a state of compression between $1 \mathrm{~N} / \mathrm{mm}^{2}$ and $13 \mathrm{~N} / \mathrm{mm}^{2}$, inside closed cells of thermoformed Mater- $\mathrm{Bi}{ }^{\circledR}$, all contained within a shell. Desired shapes and sizes can be obtained by using different moulds. To prevent the bio-plastic from adhering to the internal surfaces of the mould, it is possible to cover the inner surface of the cover/piston with a releasing material, such as a mixture of fatty acids in an aqueous emulsion. At the end of the heating phase, while the piston is kept in its final position with the fibrous material under compression, forced cooling or spontaneous material cooling is started and continues until the solidification of the bioplastic material, then the finished product is finally extracted.

Figure $1 \mathrm{C}$, shows an example of a prototype block with an extended alveolar structure. It consists of a three-directional reticulum of Mater-Bi ${ }^{\circledR}$ formed by a set of closed cells connected to one other and to the external shell, in which the bioplastic material constituting the outer shell and the walls of the cells adhere to the adjacent fibrous material. At the end of the moulding process, the straw consists of compressed fibrous stems with no single preferential orientation (arranged in all directions). This pattern is very advantageous, as the lack of a preferred direction confers good cutting resistance to the product in all directions.

\section{Testing}

Some tests were performed to characterize NeoPalea from both the mechanical and compostability points of view. Here follows a short description of the tests performed.

\section{Manufacturability of different shapes}

This test was intended to verify the capability of this material to fill a mould according to different shapes. The test was performed by producing three prototypes through the process described in the previous section. The selected geometries were defined according to the applications that the material could have in the packaging field, i.e. panels and elements with circular or angular shapes.

\section{Compression mechanical test}

The first mechanical characterization was performed to find out the elastic modulus of the compressed material. Four parallelepiped specimens with a square base of $160 \times 160 \mathrm{~mm}$, a height of $100 \mathrm{~mm}$, and a density of about $150 \mathrm{~kg} / \mathrm{m}^{3}$, were manufactured through the process described in section 3 . They were kept in the loading conditions, as they were pressed during the production phase. Each specimen was placed inside a steel die set in order to maintain the parallelism between the two contact surfaces. The loading procedure followed with the application of increasing weights until reaching the total load of about $40 \mathrm{kPa}$. This test repeated three times for each specimen. The measurement of the specimen height reduction was performed with a Mitutoyo digital centimetre comparator. The elastic modulus was determined by applying the following equation:

$\mathrm{E}=(\Delta \mathrm{F} / \mathrm{A}) /(\Delta \mathrm{l} / \mathrm{l})$

where $\mathrm{A}$ is the area of the specimen, $\Delta \mathrm{F}$ is the load variation and $\Delta \mathrm{l}$ is the corresponding variation compared to the height of the specimen 1 .

\section{Deflection mechanical test}

A second preliminary mechanical characterization was performed to determine the static elastic deflection modulus. Three thin square specimens, $160 \times 160 \mathrm{~mm}$ in size and $40 \mathrm{~mm}$ in height, and with a density of about $148 \mathrm{~kg} / \mathrm{m}^{3}$, were subjected to deflection with a single central load in the elastic range, in a perpendicular direction to that of the press during production. The specimens were placed on two movable fixtures to guarantee the isostaticity of the configuration at a fixed distance and loaded at the centre by means of a rocker arm, with weights increasing gradually up to a maximum load of $76 \mathrm{kPa}$. The test was repeated by rotating the panel by $90^{\circ}$ to observe its behaviour in the other direction of the plane. The displacement was measured at the centre using a Mitutoyo digital centimetre comparator. The elastic modulus was determined by applying Equation 2:

$\mathrm{MoE}=\left(\Delta \mathrm{F} \times \mathrm{l}^{\wedge} 3\right) /(\Delta \mathrm{f} \times \mathrm{I} \times 48)$

where MoE is the modulus of elasticity, 1 is the span, I is the second moment of area, $\Delta \mathrm{F}$ is the load increase in the elastic range and $\Delta \mathrm{f}$ is intrados displacement measured at the $\Delta \mathrm{F}$.

\section{Preliminary tests for characterisation of the viscoelastic behaviour}

For the first characterization of the viscoelastic behaviour of the material, two compression tests were performed according to the procedures described before, producing a static solution of approximately $32 \mathrm{kPa}$ for a prolonged period. The first test lasted about 9 days $(212 \mathrm{~h})$, and the second 126 days (3032 h). This test should also be considered a preliminary test for qualifying the behaviour of the material. The size of all the specimens was the same as the size of the specimens used for the compression tests.

\section{Tests for the characterisation of compostability}

The compostability was achieved according with the standard EN 13432 (European Committee for Standardization, 2002). A vermicomposting system with two different colonies of Eisenia foetida (earthworm) was used (Masciandaro et al., 2010) for prototype blocks of $160 \times 160 \times 40 \mathrm{~mm}$. The outcomes of the vermicomposting process were verified after 10 and 70 days. 


\section{Results}

The manufacturability tests were conducted on three different shapes to determine the capability of the material to fill the mould according to different configurations and to maintain the configurations suitable for packaging (Figure 2). During the production process of the prototypes, the required energy resources were those foreseen in the process model without significant variations depending on the shapes. The material filled the mould without internal voids and preserved the internal structure. Three different geometries were chosen according with the applications that the material could have for packaging. The first prototype had a brick shape (Figure 2A). The other two prototypes were generated with angles and curves: panels and elements with circular (Figure 2B) or angular shapes (Figure 2C).

The compression test demonstrated that the first of the three load cycles entails a settling of the product due to greater deformation not recovered on unloading, leading to a reduction in the specimen height between $1.15 \%$ and $1.67 \%$. The second and third cycles showed an almost complete recovery of the deformation and a much higher elastic modulus than that of the first cycle. The elastic moduli are fairly homogeneous, with an average value of
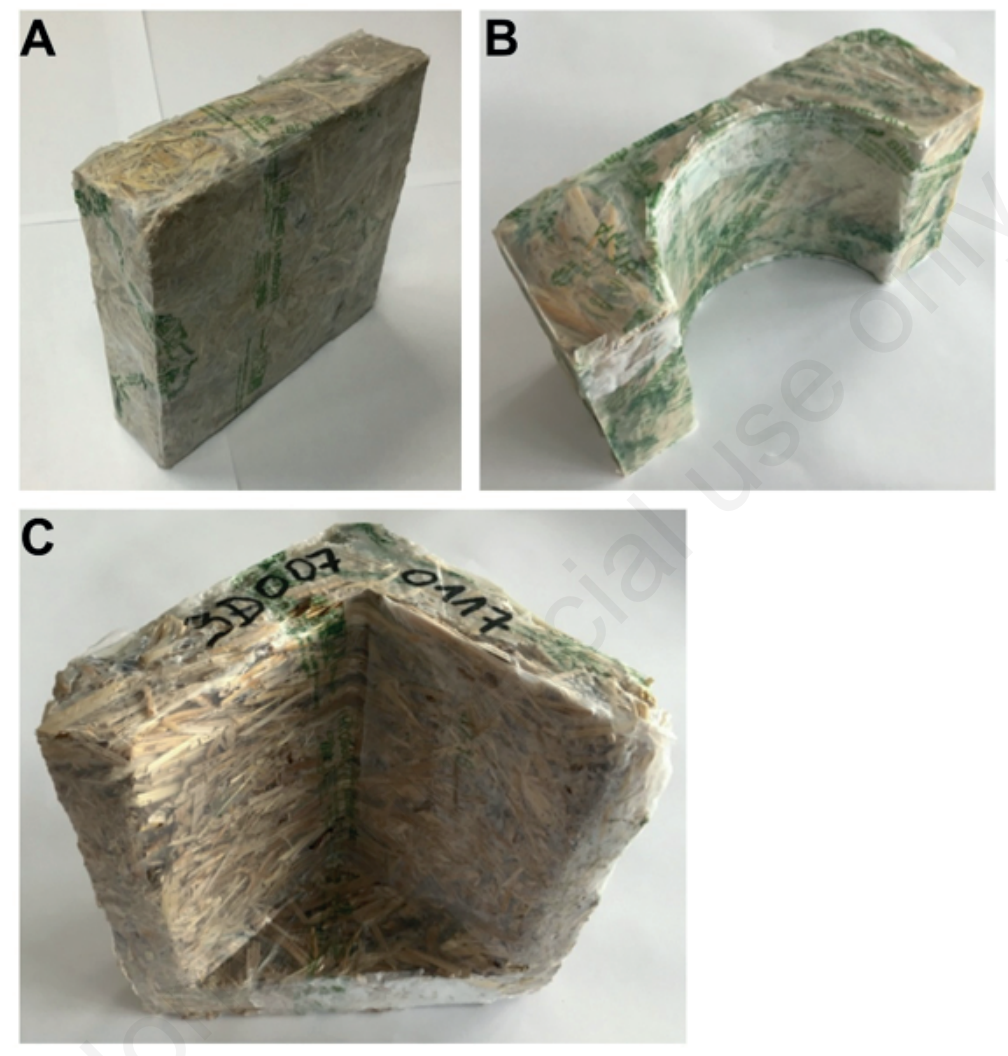

Figure 2. (A) Panel element, the material is capable to fill the mould for shapes having one dimension shorter than the others; (B) Circular element, also in this case the manufactured shape had a curve; (C) Angular element. Possible applications concern tertiary packaging for household appliances, electronic devices and glassworks.

Table 1. Results of the compression tests.

\begin{tabular}{|c|c|c|c|c|c|}
\hline \multirow{2}{*}{ Elasticity (E) } & \multirow[b]{2}{*}{ Specimen measuring unit } & \multicolumn{4}{|c|}{ Specimen } \\
\hline & & 1 & 2 & 3 & 4 \\
\hline E1 - $1^{\text {st }}$ cycle & $\mathrm{N} / \mathrm{mm}^{2}$ & 1.11 & 1.08 & 0.93 & 0.97 \\
\hline E2 - $2^{\text {nd }}$ cycle & $\mathrm{N} / \mathrm{mm}^{2}$ & 1.80 & 2.10 & 1.92 & 1.96 \\
\hline E3 - $3^{\text {rd }}$ cycle & $\mathrm{N} / \mathrm{mm}^{2}$ & 1.68 & 2.10 & 1.90 & 1.98 \\
\hline Mean E2-3 & $\mathrm{N} / \mathrm{mm}^{2}$ & 1.74 & 2.10 & 1.91 & 1.97 \\
\hline \multicolumn{6}{|c|}{ Residual displacement (fr) } \\
\hline frl $-1^{\text {st }}$ cycle & $\mathrm{mm}$ & 1.15 & 1.37 & 1.82 & 1.62 \\
\hline fr2 - $2^{\text {nd }}$ cycle & $\mathrm{mm}$ & 0.16 & 0.11 & 0.20 & 0.11 \\
\hline fr3 $-3^{\text {rd }}$ cycle & $\mathrm{mm}$ & 0.11 & 0.08 & 0.16 & 0.06 \\
\hline Mean fr2-3 & $\mathrm{mm}$ & 0.14 & 0.09 & 0.18 & 0.08 \\
\hline
\end{tabular}


around $2 \mathrm{~N} / \mathrm{mm}^{2}$ as shown in Table 1 . The results of all the cycles conducted were reported on a single graph to facilitate the comparison (Figure 3A).

The static deflection test showed an elastic modulus similar to that of the compressed specimens (Figure 3B and Table 2). The elasticity is different in the two directions of the plane with a ratio of between 1.45 and 2.19. Also, in the short-term deflection test, the creep phenomena are triggered: a sliding can be observed, with an increase in the displacement and, on unloading, a part of the deformation which is not recovered in the short term.

The maximum elastic modulus is $7 \mathrm{~N} / \mathrm{mm}^{2}$, the minimum 1.2 $\mathrm{N} / \mathrm{mm}^{2}$, with elevated variability. Within the same test, the ratio between the best elastic modulus obtained in one direction, and the other in the perpendicular direction is between about 1.5 and more than 2 . The variability in general and a sort of anisotropy of each product in particular can be partially justified by the lack of uniformity in the arrangement of the straw and the bioplastics (Figures $1 \mathrm{C}$ and $3 \mathrm{~B}$ ).

The viscoelasticity compression test showed a significant compaction during the first days of application of the load, with a progressive lowering reduction, until it reached its stability. At the end of the first test, on unloading, a residual deformation of $0.8 \%$ remained, while in the second test it was $1.7 \%$ (Figure $3 \mathrm{C}$ ). It can therefore be stated that the specimen stressed to approximately 30 $\mathrm{kPa}$ stabilizes after a period of approximately 80 days.

Finally, the vermicomposting process was also tested to measure compostability. Two colonies of Eisenia foetida provided the same outputs after 10 days. In both samples some bioplastic residues were visible (Figure 4A). They completely disappeared after 70 days, when the material had been digested almost completely (Figure 4B).

\section{Discussion and conclusions}

The objective of this research was to investigate a potential use of a combination of straw and bioplastic to replace plastics for packaging. The design of the new proposed material was developed on the basis of four main requirements: i) the reduction of the environmental impact of the entire product life cycle compared to common materials; ii) the improvement of performance in terms of protection and safety of the products; iii) the increase in competitiveness in terms of costs with respect to traditional materials; iv) full compliance with the relevant regulations (Svanes et al., 2010). In addition, the production of this material does not use any degrading chemicals during the production process, and the use of water is virtually excluded throughout the entire process.

The pre-compressed state and the particular arrangement of the straw fibres, generated through the manufacturing process, makes this material stiffer than other similar materials recently developed, which are based on mixing straw pulp with binder. For instance, in Curling et al. (2017), a material obtained by the combination of a
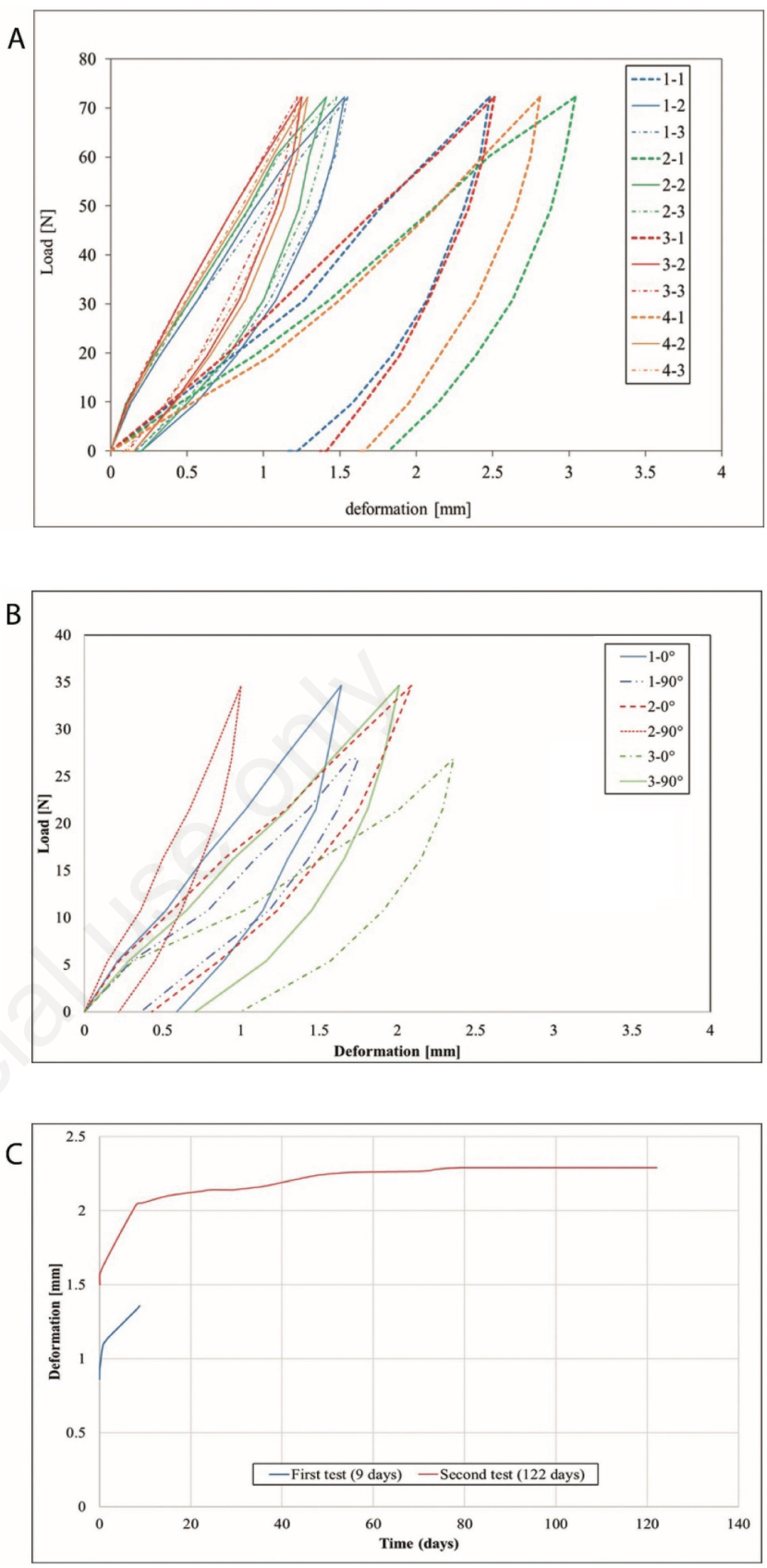

Figure 3. (A) Load-deformation graph of the compression tests. The first number in the caption represents the specimen replica, while the second number is the cycle; (B) Load-deformation graph of the bending tests. The first number in the caption represents the specimen replica, while the second number is the bending angle; (C) Deformation-time graph of the creep tests.

Table 2. Results of the deflection tests.

\begin{tabular}{lcccccc} 
Specimen no. & 1 & 2 & 3 & Average & St. dev. \\
MoE & & & & & \\
Best $\left[\mathrm{N} / \mathrm{mm}^{2}\right]$ & 2.54 & 7.04 & 1.90 & 3.83 & 2.81 & $73.3 \%$ \\
Worst $\left[\mathrm{N} / \mathrm{mm}^{2}\right]$ & 1.75 & 3.21 & 1.20 & 2.06 & 1.04 & $50.5 \%$ \\
Ratio best/worst & 1.45 & 2.19 & 1.57 & 1.40 & 1.01 & $72.2 \%$ \\
\hline
\end{tabular}

St. dev., standard deviation; $\mathrm{CoV}$, covariance; $\mathrm{MoE}$, modulus of elasticity. 
straw pulp and the binder Kraft is presented and analysed to investigate its potential use for manufacturing packaging elements. A comparison between the mechanical characteristics of the latter and those of NeoPalea (Table 3) showed that NeoPalea outperforms the mixed straw pulp.

Furthermore, when the mechanical characteristics of NeoPalea were compared with those of polystyrene for packaging (Table 3), the results showed that the mechanical characteristics of NeoPalea are overall promising. This is especially true for MoE, although the density of polystyrene is five times lower. However, during the moulding phase, the density of NeoPalea can be managed by adjusting the pressure in order to obtain a good compromise between the weight of the final product and its mechanical characteristics.

Therefore, the characterization of pressure, density and mechanical characteristics of the final product becomes a crucial investigation activity to gain further knowledge with a view to design production processes tailored to the proposed material. The viscoelastic behaviour also requires further investigations.

As can be seen in the relevant literature, some laboratories are currently developing various composite materials made of fibrous materials (also straw) and binders for the production of structural and non-structural elements. Bio-plastics are also an important component of the new material, especially because none of the systems envisages the production of elements made of exclusively of one compostable material. Indeed, the use of bioplastics or lignocellulosic fibres alone in the packaging sector presents numerous limitations, especially as structural elements. For example, the compression of fibrous materials of natural origin alone does not confer any load-bearing capacity. The combination of both materials, therefore, seems to be the best choice.

A number of patents using straw or other natural fibres are developed to build composite materials by using different kinds of binders and technological processes. Many of these patents are developed to produce brick tiles. In a patent (Shezhang, 2013) a structural board was presented, made of hot-pressed straw formed by a number of layers and isocyanate resin as binding agent. Another patent (Yongli et al., 2014) refers to brick tiles made of bamboo and straw, hot-compressed and cooled. Yet another patent (Kelin, 2012) is based on a method for the production of tiles and prefabricated components with stalks of various species, weeds, and an adhesive with a base of polyurethane foam. Another patent (Ruskey, 2005) covers blocks made of rice straw and isocyanate adhesives (and other binding material not natural), for the construction of walls of buildings. Another patent (Eagan, 1996) presents a machine for hammering, mixing with additives, laying, and pressing fibrous materials (amongst which also straw) in order to produce building blocks. The binder used is an adhesive or alternatively a cement (mortar, etc.). Eventually, in an old patent (Charriere, 1989) a heat-shrinking system is used that includes a layer of straw (or alternatively various polymers, such as expanded polyurethane or polystyrene, or waste products) for the production of building blocks.

NeoPalea can be used for various applications, not only for

Table 3. Comparison of mechanical characteristics of other materials against our proposed material NeoPalea.

\begin{tabular}{|c|c|c|c|}
\hline Material & Density $\left(\mathrm{kg} / \mathrm{m}^{3}\right)$ & Tensile modulus $\left(\mathrm{N} / \mathrm{mm}^{2}\right)$ & MoE under bending $\left(\mathrm{N} / \mathrm{mm}^{2}\right)$ \\
\hline EPS* & $33.20 \pm 0.9^{\circ}$ & $0.16 \pm 0.009$ & $0.035 \pm 0.007$ \\
\hline Curling et al., 2017\# & $147.15 \pm 3.4$ & $0.68 \pm 0.04$ & $0.028 \pm 0.006$ \\
\hline Proposed material & $149.00 \pm 1$ & $1.855 \pm 0.115$ & $2.945 \pm 0.885$ \\
\hline
\end{tabular}

MoE, modulus of elasticity. *Polystyrene; ${ }^{\circ}$ Standard deviations after \pm ; Pulp of straw mixed with a binding substance.
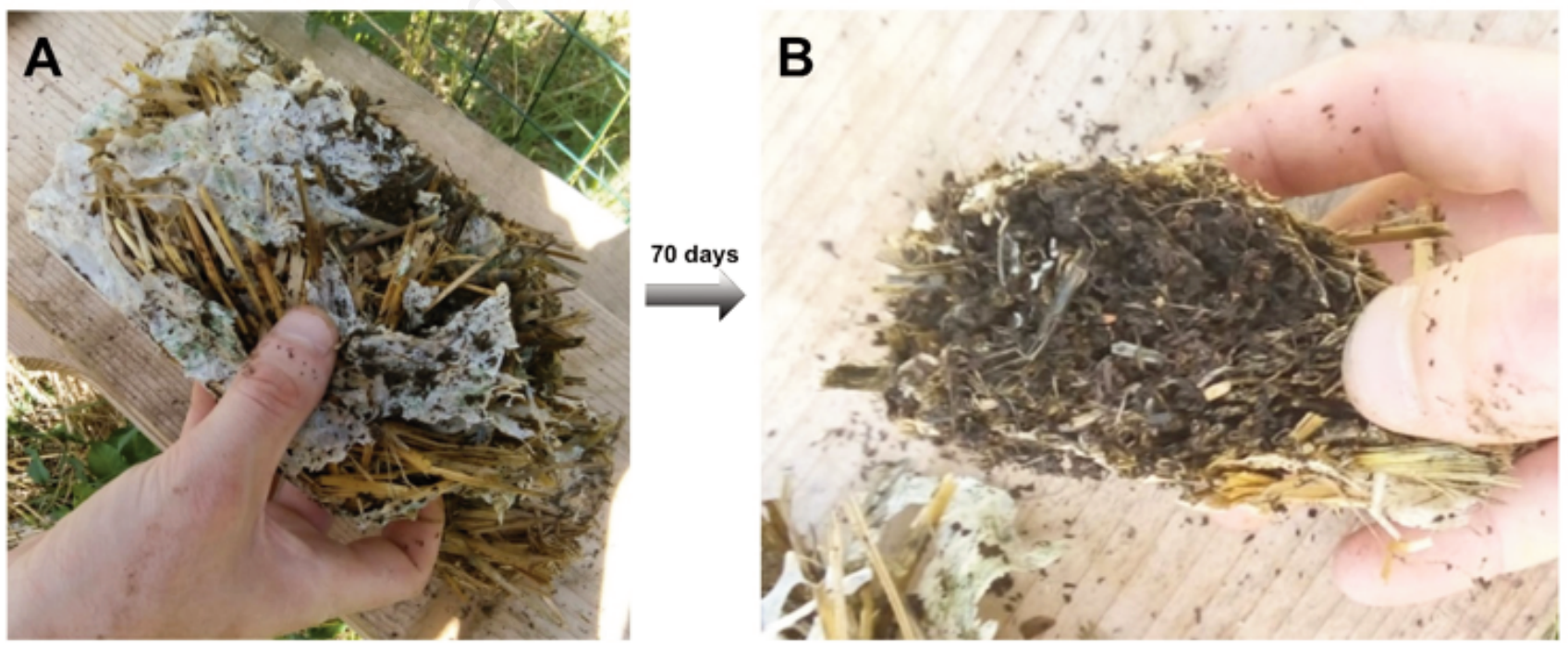

Figure 4. Degradation of NeoPalea through vermicomposting. (A) Organic residues after 10 days in the vermicomposting process. Some bioplastic is still visible. (B) Organic residues after 70 days in the vermicomposting process. All organic materials including bioplastic were degraded. 
packaging. One of the possible uses is the production of blocks. In this case, it would be necessary to provide a modular conformation, with the prearrangement of recesses and protrusions positioned randomly upwards, downwards and/or laterally to allow for the mutual positioning of several elements. Other use of NeoPalea could be the production of bricks for constructions, insulating panels, packaging for large objects.

It is also important to better assess the degradation process and compostability of NeoPalea. In terms of composting, the disaggregation of the specimens was obtained within a few weeks. However, further microbiological tests should be done for the identification of more effective degrading bacterial and fungal strains through meta-taxonomic and meta-genomic analyses of the microbial communities of the worms' gut. This understanding would lead to targeted biochemical procedures, which could offer faster and more complete degradation.

The authors intend to continue the characterization of this type of eco-friendly materials in order to identify future applications in different contexts, such as the furnishing sector, in disposable/composite exhibition installations, in the production of food containers (fruit, meat, fish), and other artefacts that are currently made of plastic materials. Accordingly, the development of methods to support the functional design of products made by NeoPalea is a relevant future research activity to speed-up its industrial uptake. A further step will be the determination of the environmental performance of this material and its entire industrial process as well as the environmental impact of its supply chain by exploiting the life cycle analysis methodology (Wikström et al., 2014). Finally, tests should be conducted using other organic waste materials different from straw. The advantage of being able to pack organic material together with thermo-melting biopolymers will surely provide applications with wide margins of flexibility and ecological applications. This will support additional applications, such as for food packaging with thinner, strong and clean structures. The expected impact of this research is of paramount importance, due to the critical use of packaging in almost any production and/or commercial process, where the use of plastic is still extremely wide, despite its impact on the Earth's health.

\section{References}

Babalis A., Ntintakis I., Chaidas D., Makris A. 2013. Design and development of innovative packaging for agricultural products. Procedia Tech. 8:575-9.

Bhattacharyya P., Bhaduri D., Adak T., Munda S., Satapathy B.S., Dash P.K., Padhy S.R., Pattanayak A., Routray S., Chakraborti M., Baig M.J., Mukherjee A.K., Nayak A.K., Pathak H. 2019. Characterization of rice straw from major cultivars for best alternative industrial uses to cutoff the menace of straw burning. Ind. Crops Prod. 143:111919.

Brodin M., Vallejos M., Opedal M.T., Area M.C., Chinga-Carrasco G. 2017. Lignocellulosics as sustainable resources for production of bioplastics - A review. J. Cleaner Prod. 16:646-64.

Charriere J.J. 1989. Composite article comprising a central core wrapped in a cover, and its uses. Patent number: EP 0345125A1.

Cherubini F., Ulgiati S. 2010. Crop residues as raw materials for biorefinery systems - A LCA case study. Appl. Energy 87:47-57.

CONAI, 2017. L'Economia Circolare in Italia: la voce delle aziende produttrici e utilizzatrici di imballaggi. Milan, Italy. DOI: 10.13140/RG.2.2.33460.86402. [in Italian].
Conti L., Dainelli R., Pellegrini P., Spugnoli P., Bonotti L. 2012. Study of sustainable agricultural supply chains for the production of construction straw bales - Preliminary results. pp 239250 in: Proceedings of rural building between technological development and protection of the territory, 2012, 20-22 September, Florence, Italy [in Italian].

Curling S.F., Laflin N., Davies G., Ormondroyd G.A., Elias R.M. 2017. Feasibility of using straw in a strong, thin, pulp moulded packaging material. Ind. Crops and Prod. 97:395-400.

Dahlbo H., Poliakova V., Mylläri V., Sahimaa O., Anderson R. 2018. Recycling potential of post-consumer plastic packaging waste in Finland. Waste Manag. 71:52-61.

Eagan S.A. 1996. Process and apparatus for forming a building block. Patent number: US 5507988A.

European Committee for Standardization, 2002. DIN EN 13432 Requirements for packaging recoverable through composting and biodegradation. Test scheme and evaluation criteria for the final acceptance of packaging. Brussels.

European Committee for Standardization, 2010. Plastics Recommendation for terminology and characterization of biopolymers and bioplastics - CEN/TR 15932. Brussels.

FAO. 2020. Crop prospects and food situation - Quarterly global report No. 1, March 2020. Rome. Available from: https://doi.org/10.4060/ca8032en

Garrido T., Etxabide A., Leceta I., Cabezudo S., De La Caba K., Guerrero P. 2014. Valorization of soya by-products for sustainable packaging. J. Cleaner Prod. 64:228-33.

Kelin M. 2012. Method for producing bricks and prefabricated parts used for building by utilizing weeds and crop straw. China patent CN 102328336A.

Masciandaro G., Bianchi V., Macci C., Peruzzi E., Doni S., Ceccanti B., Iannelli T. 2010. Ecological and agronomical perspectives of vermicompost utilization in Mediterranean agroecosystems. Dyn. Soil Dyn. Plant 4:76-82.

Meeks D., Hottle T., Bilec,M.M., Landis A.E. 2015. Compostable biopolymer use in the real world: Stakeholder interviews to better understand the motivations and realities of use and disposal in the US. Resour. Cons. Recyc. 105:134-42.

Nordin N., Selke S. 2010. Social aspect of sustainable packaging. Pack. Tech. Sci. 23:317-26.

Ruskey J.A. 2005. Culm blocks. Patent number: US 6951080B2.

Russo G., Verdiani G. 2013. Production and reuse of waste in rural area with high density of greenhouse. J. Agricult. Engine. XLIV:240-6.

Shezhang G. 2013. Oriented structural straw board and preparation method. Patent number: CN 103448107A.

Svanes E., Void M., Møller H., Pettersen M.K., Larsen H., Hanssen O.J. 2010. Sustainable packaging design: A holistic methodology for packaging design. Pack. Tech. Science 23:161-75.

Tencati A., Pogutz S., Moda B., Brambilla M., Cacia C. 2016. Prevention policies addressing packaging and packaging waste: Some emerging trends. Waste Manag. 56:35-45.

Wikström F., Williams H., Verghese K., Clune S. 2014. The influence of packaging attributes on consumer behaviour in foodpackaging life cycle assessment studies - A neglected topic. J. Cleaner Prod. 73:100-8.

Yongli G., Haitao L., Shuheng L., Jingwen S., Shiwen S., Qisheng Z. 2014. Bamboo scrimber straw brick, bamboo laminated wood straw brick and preparing method thereof. Patent number: CN 103538138A. 